\title{
Criteria for promotion of low energy buildings in Europe. The Italian case
}

\author{
Andrea Boeri and Danila Longo \\ University of Bologna, Department of Architecture and Territorial Planning \\ Faculty of Architecture "Aldo Rossi", Cesena \\ Italy
}

\section{Introduction}

The climatic context has an essential role in the design strategy to adopt: it is the main benchmark to define criteria for energy-efficient buildings design. The Italian one has predominantly Mediterranean characteristics which differ from cold climates of central and northern Europe, where major researches and applications concerning the containment of energy in buildings were conducted. In countries that have developed lots of experiences, such as Germany, Austria, Switzerland and Scandinavian countries, the researches on energy efficiency and the concept of passive building refer to contexts characterized by harsh winters - where the priority is the containment of the heat dispersion - and summers with overheating conditions. The buildings have mainly to ensure high levels of thermal insulation to contain the dispersion in the winter; the glazed surfaces should allow the incoming of solar radiation useful for lighting and passive heating of the interiors, keeping down the overall transmittance of the building shell.

In these contexts issues related to summer heat and to the presence of moisture, typical of many areas of Italy, are less important. Italian regions have more differentiated climates: according to the seasons protection from summer heat or the energy containment during the winter have different importance. In the alternation of seasons the buildings have to answer to cold winters and hot summers, often with high humidity, providing adequate performances in different conditions.

In southern and central Italy the main factor is the heat control that regards just the summer period, during which situations of overheating - that imply relevant energy consumption due to conditioning systems - shall be limited. It is possible that the energy required to cool the buildings exceeds the requirements for heating.

The indicator of climatic conditions commonly used is the value of degrees day (HGT), an indicator of climatic conditions of the area. According to the D.P.R. n. 412 of 1993 they are the sum, extended to every day of a conventional heating year, of the only positive differences between the daily temperature, conventionally set at $20^{\circ} \mathrm{C}$, and the average external daily temperature. The value of HGT in the specific location is proportional to the need for heating of buildings, linked to the need for heating of buildings in specific locations. 
This implies that the criteria for energy efficiency projects, developed and codified mainly in cold contexts, should be revisited and adapted to specific national climatic situations, even recovering and updating design criteria and techniques adopted in traditional building.

\section{Requirements and performances in national context}

Italian territory is characterized by different climates, variables from predominantly cold (Alpine) to warm (southern regions and islands) ones, and areas with temperature variations related to significant seasonal cycles. The recent growing attention to the issue of buildings energy efficiency puts the stress on the technical and regulatory problems related to the search for solutions adapted to specific environmental conditions. Therefore it is necessary to define design solutions to respond to different climatic conditions, to contain energy consumption during the winter and to limit the interior overheating during the summer. The main energy consumption in management phase of buildings regards the need of heating during the winter and/or cooling in the summer. The national decrees, transposition of European Directive 2002/91/EC, providing different limits for indicator of energy performance for the winter climate, expressed in $\mathrm{kWh} /$ year per unit of area or volume depending on the climatic zone of reference, apply an early diversification according to the weather conditions. The six climatic zones of Italy comprise the range from A, hotter with less than 600 HGT to F, with colder than 3000 HGT, through four intermediate zones. The different prescription of thresholds of consumption for heating in the winter responds to different climatic conditions on the country, a factor to be considered in regulations or energy efficiency classification.

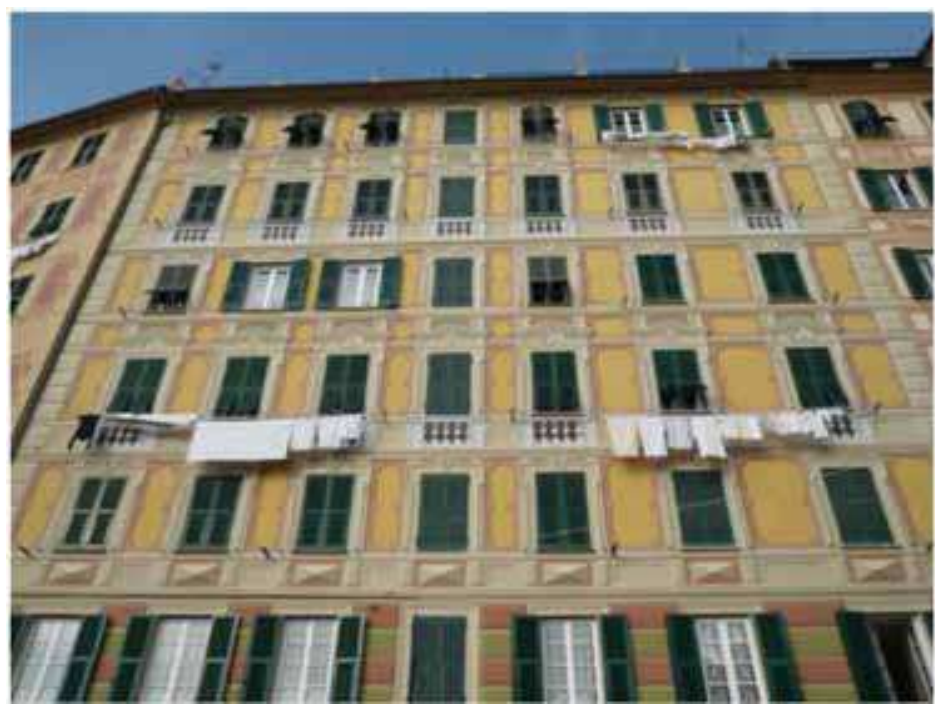

Fig. 1. Typical buildings of the Ligurian coast

The energy performance for the winter climate responds, first of all, to needs for containment of heat loss. The presence of an effective system of thermal insulation, 
especially if it is placed outside the wall, has a beneficial effect, reducing significantly the summer heat transfer from the outside during the warm seasons.

A normative aspect, aimed at limiting overheating, concerns the lower limit of $230 \mathrm{Kg} / \mathrm{m} 2$ for the value of the mass of the opaque envelope. It refers to every climatic zone except $\mathrm{F}$, in localities where the monthly mean value of irradiation of the horizontal plane, in the month of maximum summer insulation, is greater than or equal to $290 \mathrm{~W} / \mathrm{m} 2$.

By defining this minimum conventional value, the building in hot areas characterized by the minimum indicated irradiance, shall have an envelope with adequate mass, proportional with thermal inertia of its elements. It is the combined effect of the capacity of accumulation and heat resistance of the structure, to obtain adequate thermal damping and time lag of external variations of temperatures inside the building.

Other regulatory issues include the requirement of shielding systems for glazed surfaces to reduce the contribution of solar heat due to radiation in the summer and the use of external environmental conditions and characteristics of distribution of spaces to promote natural ventilation, possibly supplemented by mechanical ventilation systems.

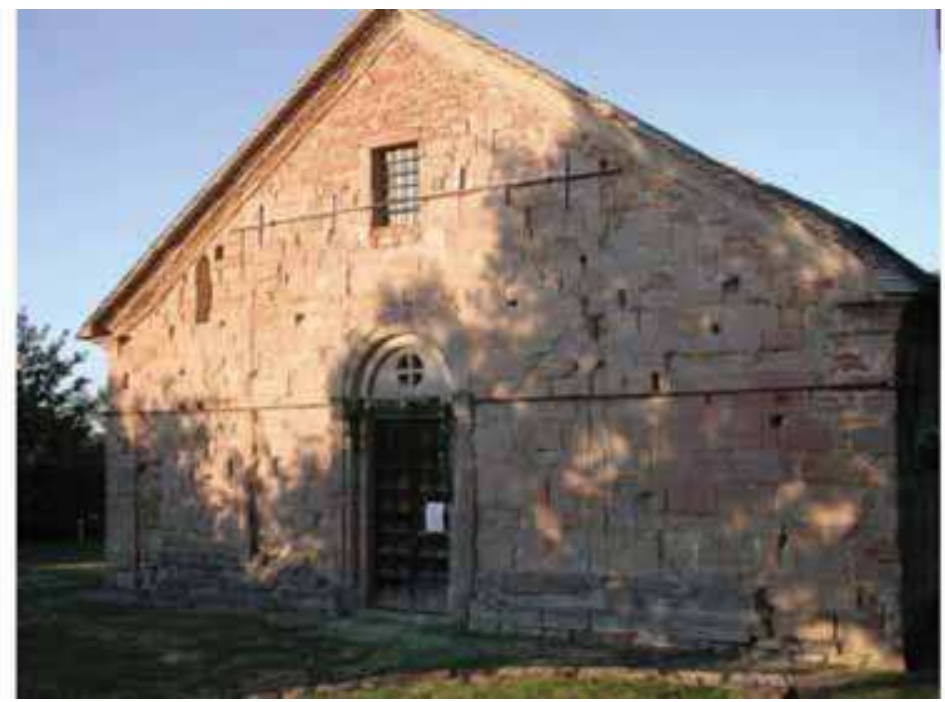

Fig. 2. Historical building. The Italian traditional architecture is characterised by envelopes built with considerable mass materials.

\section{The standard and the criteria of Passive house}

Having briefly outlined the national state of the art, characterized by significant climatic differences that have correspondence in regulatory requirements, it is interesting to note how the concept of passive house, born in the colder climates of central Europe, is developing with adaptive criteria in other countries. 


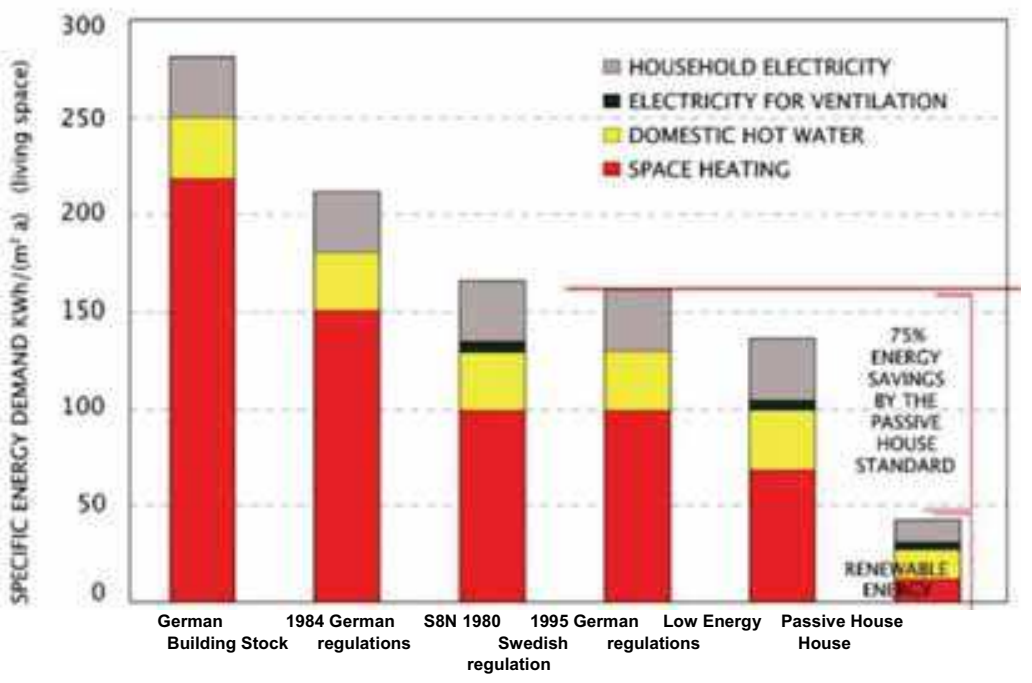

Fig. 3. Histogram that compares energy consumption in residential buildings of different European countries. Data from site httpwww.passiv.de

In particular the Passive-On research project, sponsored by the EU SAVE Intelligent Energy, which aims to promote the passive houses in warm climates is very interesting. The concept, developed first by Passivhaus Institute in Darmstadt, has been deepened by researches and trials in Europe, such as the CEPHEUS - Cost Efficient Passive Houses as European Standards project on the potentials of an alternative approach to the issue of energy use in buildings, designing solutions and suggesting technologies for buildings that can consume minimal amounts of energy during their life cycle, without increasing the cost of construction.

The passive house consumes limited amount of energy for its management and doesn't use fossil fuels, using only minimal amounts of auxiliary energy: the original codification restricted the annual requirements for heating in not more than $15 \mathrm{kWh} / \mathrm{m}^{2}$ and the total of domestic consumption (hot water, cooling, lighting, appliances) not more than $42 \mathrm{kWh} / \mathrm{m}^{2}$. Adapting the concept to the warmer climates it is necessary to take into account the specific needs for cooling, also using mechanical systems. Therefore the annual limits for heating were defined in $15 \mathrm{kWh} / \mathrm{m}^{2}, 15 \mathrm{kWh} / \mathrm{m}^{2}$ for cooling and $120 \mathrm{kWh} / \mathrm{m}^{2}$ for total primary energy for all consumption.

The experiments in progress on passive designing in hot climate, similar to what happened in cold climates, will be a reference to the development and application of more progressively efficient buildings. 


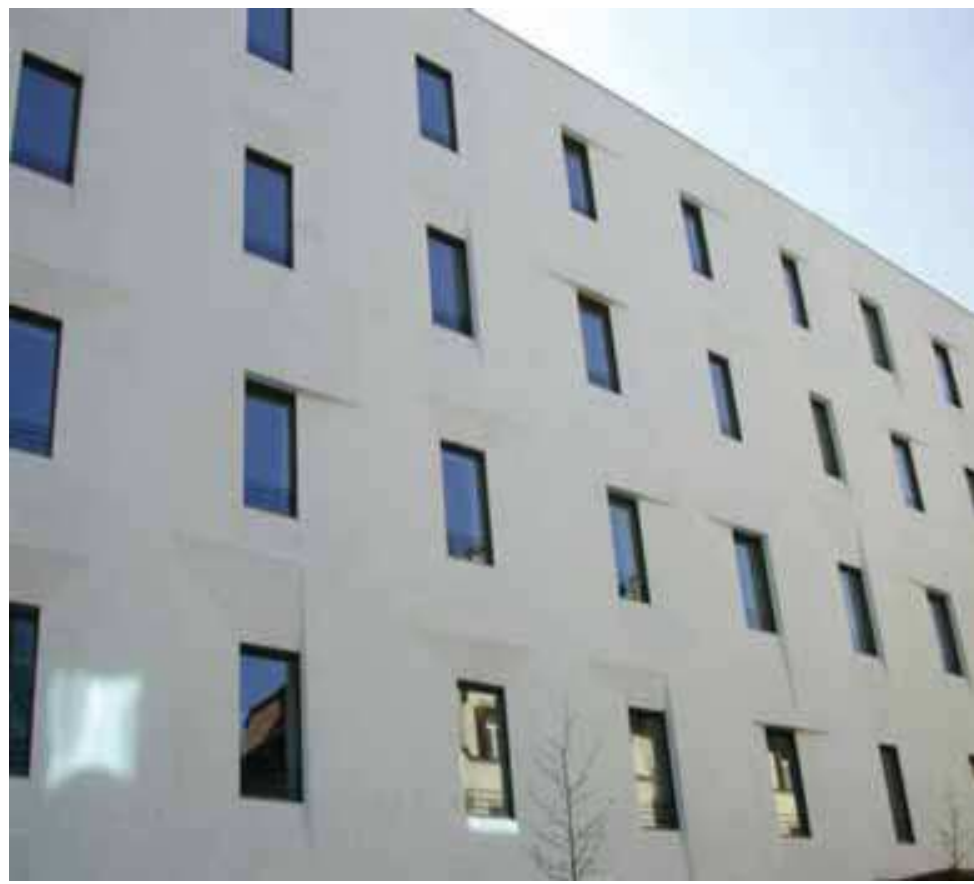

Fig. 4. Energy retrofit of the new headquarters of the Autonomous Province of Bolzano, arch. M. Tribus. This is the first national public building with a consumption of only 12 $\mathrm{kWh} / \mathrm{m} 2$ year for heating. It reaches the European standard of passive house. There is an outer coat of sintered polystyrene insulation $35-\mathrm{cm}$ thick.

\section{Design aspects}

The passive houses are characterized by design criteria focused on energy efficiency of the integrated building systems, pursing energy saving, minimizing the active fixtures and fittings, powered by energy.

Since the heat exchange between inside and outside carries out through the building envelope, it is important to use a compact building shell, and take advantage of opportunities to combine buildings, use a simple shell form, and minimize shaded areas in winter. It is fundamental the shape of the building and in particular the relationship between all dispersing surfaces and the heated or cooled volume. The passive standard provides that the limit of the S/V ratio, that is to say the index of compactness (the same also provided by national legislation), is not greater than 0.6. Buildings characterized by a compact form and a considerable volume imply a minor thermal exchanges. This consideration is valid in general even in hot context. While increasing the dispersant surface, the building form has to favor the natural ventilation, necessary for cooling during the night.

There are several typological examples to refer, such as traditional "domus italic". The continuity of the insulation layer and the quality of shell components have a dual purpose: to avoid the spread of heat during the winter and overheating during the summer. In 
relation to climatic conditions these functions, generally integrated, are important. In countries of central Europe and north Italy characterized by a hard winter, the dispersion control during this period is important, while in the Mediterranean areas the summer performances of buildings must be controlled.

So, the designer has to determine insulation thickness of building envelope and avoid heat bridges.

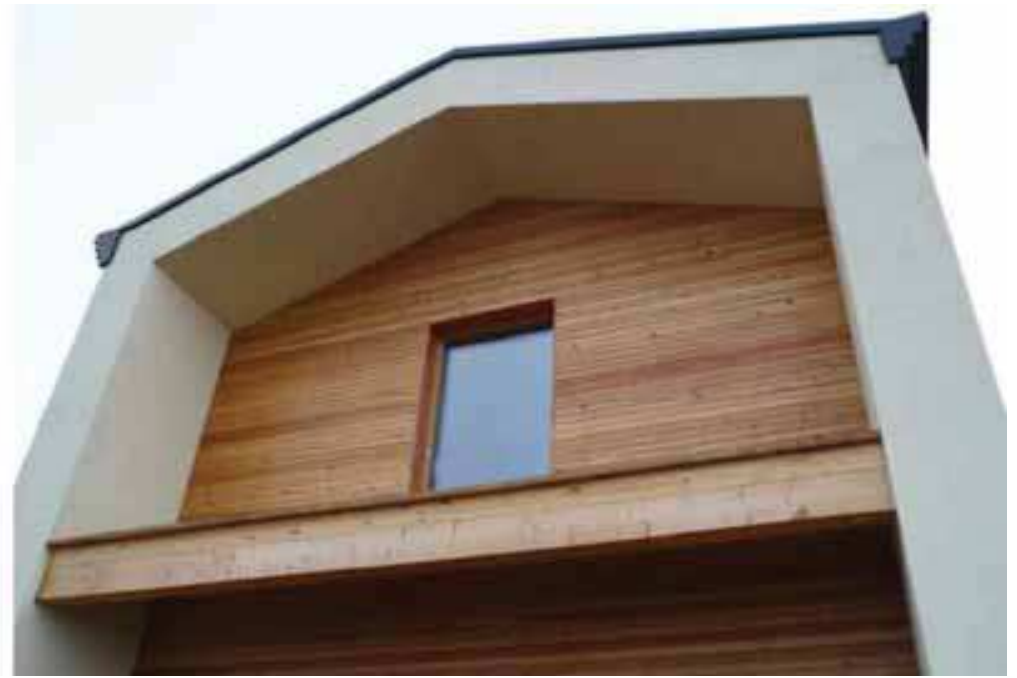

Fig. 5. Passive residential building in Montiano (FC - Italy), designed by Oficina 4, arch. G. Borghetti. The regular and compact shape helps the energy control; the orientation and limited size of transparent surfaces limit summer overheating.

To keep to passivhaus standard (U-factor that does not exceed $0.15 \mathrm{~W} /\left(\mathrm{m}^{2} \mathrm{~K}\right.$ ) the components of the shell must have an insulation thickness of about $25 \mathrm{~cm}$ on the vertical walls, even more on coverage. The solution of isolation on the outer side of the wall, like a coat, avoids heat bridges (the transmittance of linear thermal bridge must be less than 0.01 $\mathrm{W} / \mathrm{mK}$ ) and protects the thermal mass of the structure, allowing the regulation of indoor comfort.

To complete the building shell also glazed surfaces must be extremely efficient: in cold climates to achieve the required standard (less than $0.8 \mathrm{~W} / \mathrm{m}^{2} \mathrm{~K}$ ) it is important to use windows with thermal insulated frame and triple-glazing with inert gas (argon, krypton), special low emissivity glasses, very transparent. In warm climates it is possible to obtain adequate results with insulating glasses and high performance frames (transmittance: between 1 and $1.2 \mathrm{~W} / \mathrm{m}^{2} \mathrm{~K}$, depending on the layout and size of the glazed surface). It is always necessary that the windows are applied respecting the continuity of the insulation layer, which must protect the same frame.

In general, the strict limits of thermal transmittance of the building shell are sufficient, in cold climates, to ensure high performances. In warm climates the integrative role of thermal inertia of the shell components should be considered. It is ensure by the high mass material that maintain an appropriate delay time (more than 12 hours) and mitigate, according to the 
thermal resistance of the structure, the effects of the external changes of temperature on the indoor microclimate.

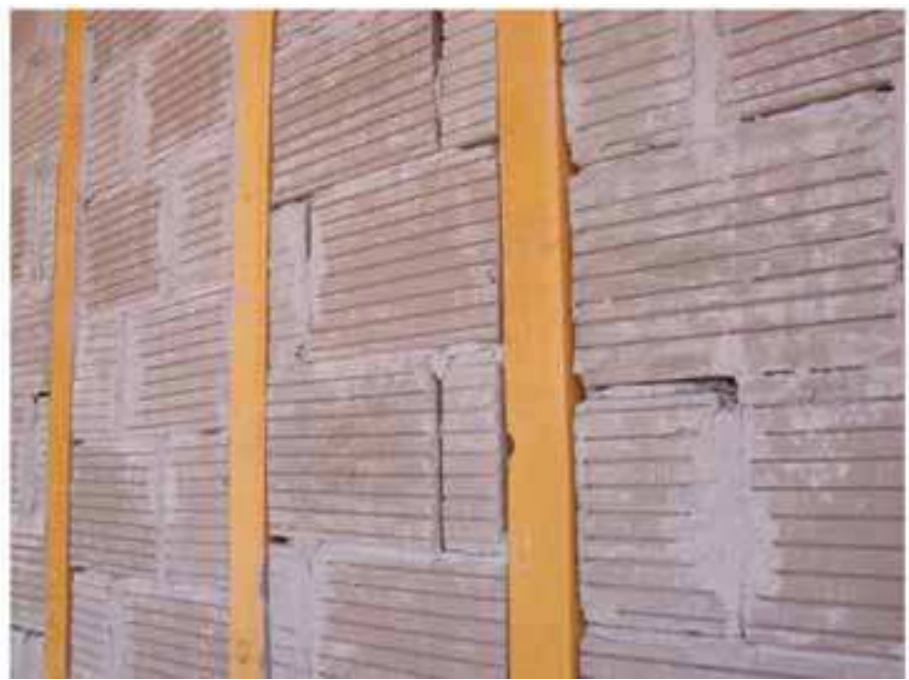

Fig. 6. The raw clay brick wall, with high heat capacity, helps to maintain equilibrium of humidity inside the building.

In order to reduce heat transmission through the shell, subjected to direct solar radiation, to the inside layers, is appropriate to use ventilated solutions for the walls and especially the roofs, which are subjected to excessive sunshine in the summer.

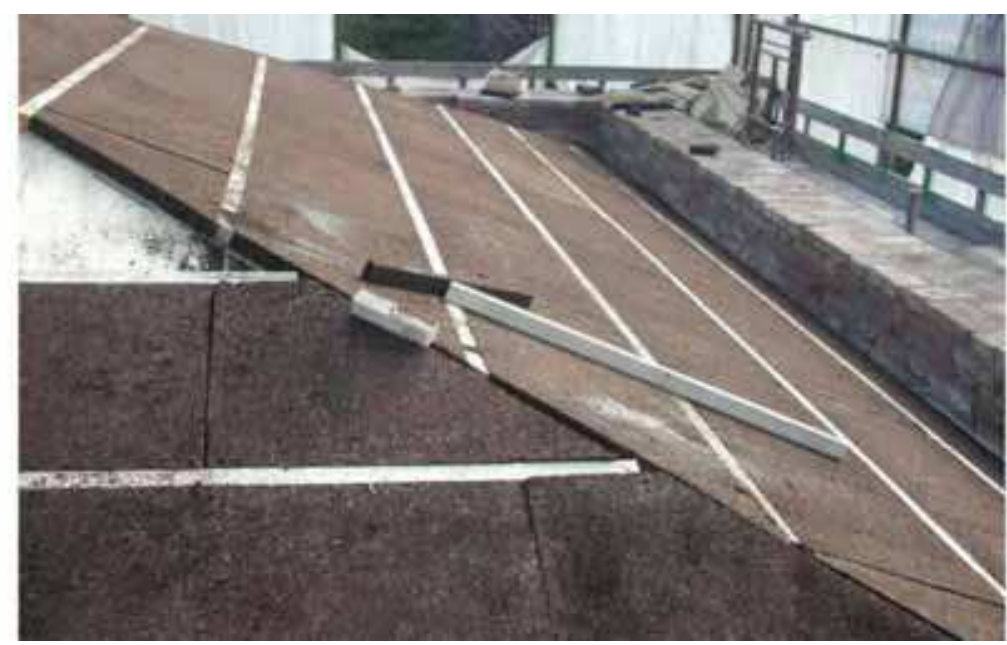

Fig. 7. Isolated and ventilated roof in historical building. The lack of adequate insulation causes excessive heat dispersion, the ventilation system favours a better summer behaviour. 
The passive use of solar energy depends on the right position and orientation of the site. South orientation of the main side $\left( \pm 30^{\circ}\right)$, and large south-facing window areas are important. South exposure is the most favorable as it receives the maximum sunlight in winter, when the sun is low in the sky and its energy contribution is significant ( $44^{\circ}$ North Latitude, December 21th: the sun in high about $23^{\circ}$ above the horizon). Instead in the summer when the solar energy is unfavorable because it tends to generate overheating inside, the sun is high in the sky (June 21: about $70^{\circ}$ above the horizon) and its beams hit on the vertical walls with high inclination. Therefore the facades are more protected from direct exposure.

However, since the exposure factors depend on conditions of the context the design criteria to define the size and orientation of the glazed surfaces should be defined with relation to the specific sites, regulating the conditions of solar capture.

South orientation of the main side receives the maximum radiation in winter, when the solar incidence is favorable, and a minor contribution in the summer. The experience has shown that on the south side the percentage of glazed surfaces in passive traditional buildings should not exceed $40 \%$ of the total facades, to limit the excessive losses due to the energy transmission.

In warmer areas this value is to be significantly reduced depending on latitude, limiting glazed surfaces to $30 \%$ of the same fagade. The exposure to solar radiation should be controlled by external shade elements. Particular attention should be pain at west windows, which contribute significantly to global overheating. The north side, little sunny and exposed to cold winds, must be closed as possible to avoid the dispersion of heat. It is important to use a building footprint that concentrates utility installation zones (e.g., bathrooms or kitchens and each other) or filter areas in this side.

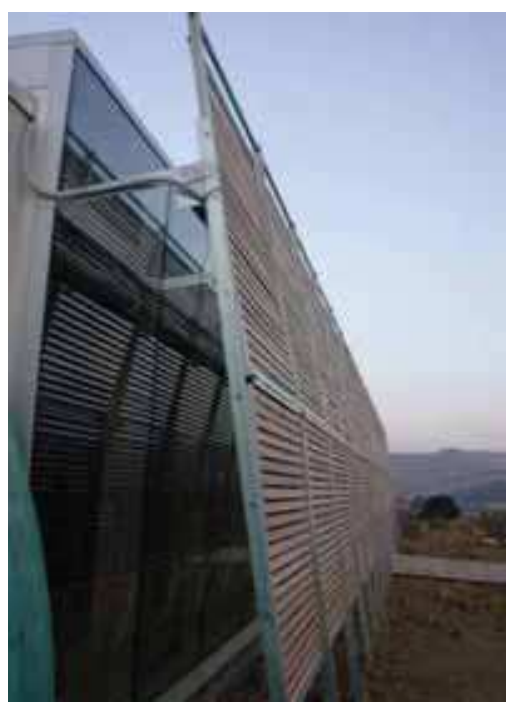




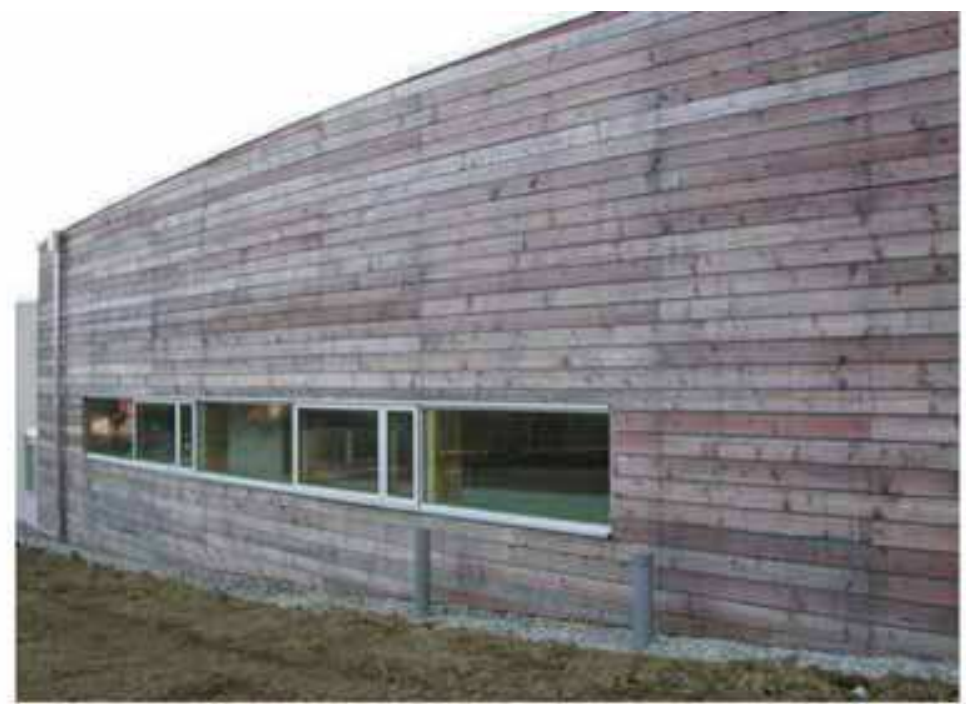

Figs. 8. - 9. The design of the School of Children in Ponticelli (Imola - Italy), arch. A. Contavalli, is characterised by energy efficiency. The north facade is extremely compact, the south one is glazed and protected by a system of external shields.

To prevent heat dispersion and infiltration through the building envelope it is necessary to drastically reduce its permeability. Passivhaus standard requires a value of waterproof less than 0.6 volumes/hour of air chance measured with a pressure difference of $50 \mathrm{~Pa}$ between inside and outside. This is a very small value: in light dry constructive solutions is possible to apply a waterproof layer under the thermal insulation; for masonry solutions is important to require the continuity of plaster. Great care should be taken to assure that insulation layers are continuous, and without air pockets, to eliminate any discontinuity of different elements of the shell (it is important to have a building shell pressure test performed). In warm climate areas the infiltration, even if negative, have less impact on energy loss, and the value of permeability can be increased to 1 volume/hour.

A passive house is a building in which a comfortable interior climate can be maintained without active heating and cooling systems (Adamson 1987 and Feist 1988). The house heats and cools itself, hence "passive". Low energy consumption to maintain the conditions of comfort is ensured by highly efficient heat recovery from exhaust air using an air-to-air heat exchanger. The mechanical ventilation has a dual function: on the one hand contributes to heat and cool the interiors, on the other allows their ventilation, necessary for the comfort indoor, avoiding the heat loss due to opening windows, providing an air supply of 30-40 $\mathrm{mc} / \mathrm{h}$ per person.

The heat from the exhausted output air flow is transferred to the incoming one through one or more heat exchangers possibly integrated with a pump. The Passivhaus standard requires a return of the heat recovery system not less than $75 \%$. To reduce the difference of heat of incoming flow, previously filtered, it may be circulated in a buried air-to-air heat exchanger consists of underground pipes, taking advantage from the thermal storage properties of the soil, which has temperatures about $10-12^{\circ} \mathrm{C}$ in depth. In winter, this step 
raises the temperature of the incoming flow, before passing through the heat exchanger. In summer often cooled air can be placed directly inside.

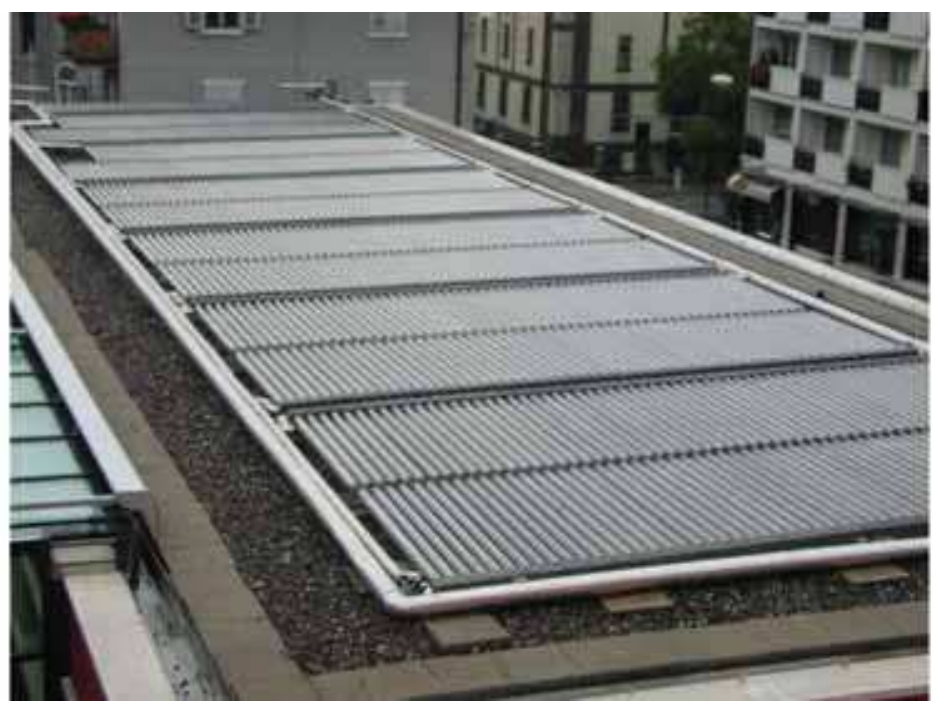

Fig. 10. Solar collectors system on the roof. It needs for hot water and heating. In the summer contributes to air conditioning inside the building.

Solar collectors or heat pumps are used for water heating. In warm climate the production with solar collectors is also sufficient for the winter: you can also integrate the collector to the heating system, providing auxiliary heat to it. Generally the collectors are placed on the coverage, but the tendency foresees to integrate them into the building envelope components.

The electricity needed for lighting, home consumptions and for ventilation fixtures are extremely low: it is important to use light sources and low energy consumption equipment. Moreover, the overall energy consumption of the Passivhaus standard, as mentioned, must be contained in $120 \mathrm{kWh} / \mathrm{m}^{2}$ of primary energy.

The installation of a photovoltaic system capable of transforming solar energy into DC (direct current) may contribute to the energy production: any unused energy quantity can be accounted for and placed in the network of distributors.

In summary the project strategy for buildings passive control in hot climates tends to minimize the internal and external heat gains and obtain appropriate levels of time lag and reduction.

All the strategies related to the removal of the summer heat are to be appreciated. If the waterproof of the envelope avoids accidental infiltration - which has a negative impact to the heat and energy balance, the exploitation of climatic context conditions in the appropriate seasons may cause considerable free benefit of charge, contributing to the reduction of inside moisture. In particular the use of night ventilation, where the outside temperature falls to levels lower than that of comfort, can help to cool the thermal mass of the building, consisting of the massive structures in contact with the indoor environment, particularly if they are protected by insulation layer. This benefit helps to reduce 
overheating during the following day. Alternative or supplementary forms consist of evaporative and geothermal cooling.

\section{The thermal insulation}

The buildings should ensure high levels of thermal insulation to contain the dispersion in the winter; the transparent parts should allow the entry of solar radiation, useful for lighting and important for its contribution for passive heating of the interiors without raising the transmittance of the building shell.

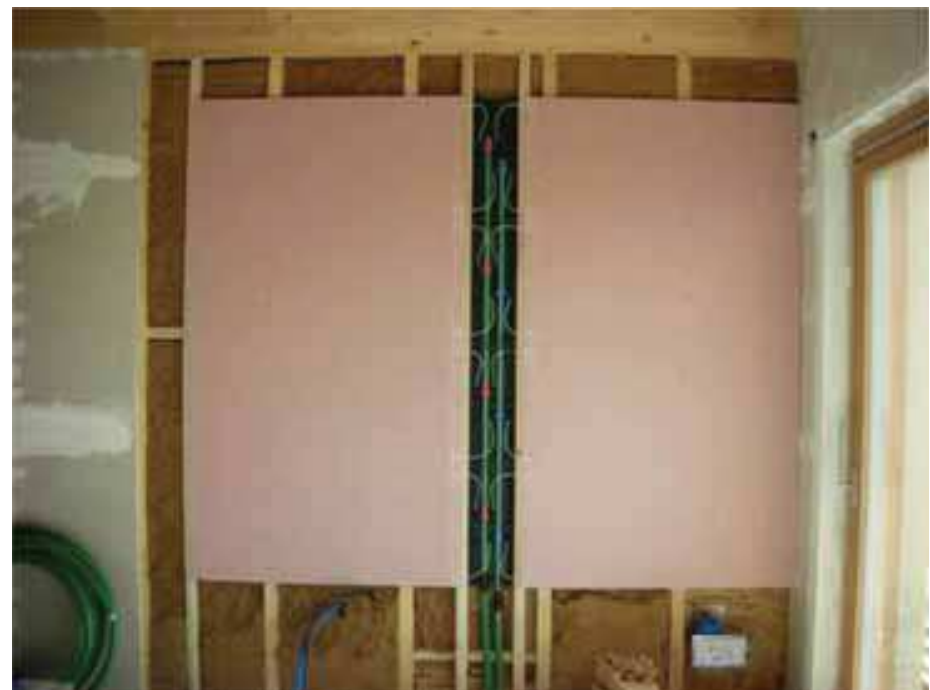

Fig. 11. Hydrothermal control system. The PCM Micronal panels contain microscopic capsules of wax that change phase between 22 and $26^{\circ} \mathrm{C}$, accumulating latent heat and contributing to maintain internal temperature limiting overheating

To ensure energy performances it is necessary that the thermal layer of the envelope is continuous and characterized by low U-factor. We can consider the high efficiency values of CasaClima as reference: the standard for Class A has a range from 0.1 to $0.2 \mathrm{~W} / \mathrm{m}^{2} \mathrm{~K}$ for private homes and from 0.15 to $0.25 \mathrm{~W} / \mathrm{m}^{2} \mathrm{~K}$ for block buildings (values are higher if the volume factor is favorable). The D.L. 311/06, amending the previous D.L. 192/05 implementing Directive 2002/91/EC on energy efficiency in construction sector, requires less restrictive values: depending on the climate zones, the values change from $0.85 \mathrm{~W} / \mathrm{m}^{2} \mathrm{~K}$ (zone A until the end of 2007) to $0.33 \mathrm{~W} / \mathrm{m}^{2} \mathrm{~K}$ (area $\mathrm{F}$ from 2010). In general, the required values of transmittance decrease from the warmer climate zones $(\mathrm{A})$ to the coldest $(\mathrm{F})$. The insulation is necessary to ensure energy efficiency: the high mass which contributes to increase the thermal inertia of the system is not sufficient to limit the thermal conductivity of the building envelope. 


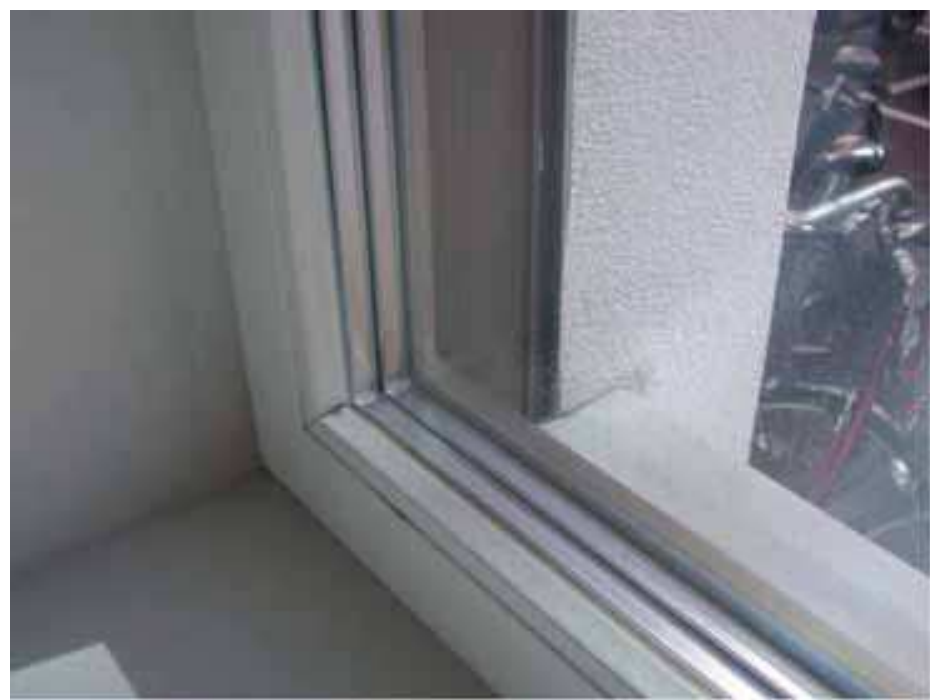

Fig. 12. External insulation. Detail of a window with triple glasses and double air interspaces

For instance, for a natural stone wall $60 \mathrm{~cm}$ thick, plastered on its sides, you can assume a value of thermal transmittance of $2,20 \mathrm{~W} / \mathrm{m}^{2} \mathrm{~K}$, about sevenfold higher than what it would be necessary to have a benefit in terms of discrete containment of energy. To limit the transmission of heat is necessary to apply appropriate layers of insulating material: in general, the monolayer constructive solutions, even using efficient elements in brick, are not sufficiently insulating in cold climates.

Light-technologies and insulated solutions for building envelope have good performances in terms of thermal transmittance, widely applied in cold climates, mostly realized with wooden frame, gap filled with insulating material, thermal layer and protective covering. With these solutions you can get very interesting and low values, of about $0.20 \mathrm{~W} / \mathrm{m}^{2} \mathrm{~K}$, due to a gap to fill with bulk insulation such as mineral wool, low thermal conductivity of wood used as a frame (the wood conifer has a thermal conductivity coefficient - in the transverse fibers - of $A=0.13 \mathrm{~W} / \mathrm{mK}$ ), which is further protected by a layer of insulation outside.

\section{The role of the mass}

If the recent researches are primarily aimed to codify appropriate construction technologies for the energy saving in winter, it seems appropriate to focus attention on climate characteristics and in particular on the passive protection from the summer heat. To increase the heat capacity of building technological layers, you can use insulation with higher thermal mass, such as panels of wood fiber (with a density ranging from 130 to $190 \mathrm{~kg} / \mathrm{m}^{3}$ ), with very good hygroscopic performances. In general, lightweight solutions have not a considerable heat capacity, that is to say that they don't contribute sufficiently to delay the transmission of external thermal variations.

If the heat insulation is the most important and codified factor from the prescriptive point of view, in relation to different climates, in particular the warm ones, the role of thermal inertia 
of the building system gradually assumes importance. It is simple to define the concept but difficult to calculate this factor: at a glance it can be defined as the combined effect of the capacity of accumulation and heat resistance of the structure.

Traditional Italian architectures such as the Apulia "trulli" and "dammusi" of Pantelleria can represent simple but interesting bioclimatic reference models: they are able to maintain sufficiently constant temperature indoor, even without auxiliary fixtures and fittings, thanks to a correct architectural form, exposure, the relationship with the soil, and in particular to the thickness and mass of the envelope.

The coefficient of thermal lag allows to evaluate the delay of transmission of the external thermal gradient changes inside. To obtain sufficient comfort conditions, lag should not be less than 8 hours, while optimal conditions are achieved with just 12 hours. Therefore, especially in the summer, in addition to the transmittance it is important to assess the contribution of the massive materials, with higher heat capacity in order to reduce the effects of external thermal variations on the microclimate indoor. The evaluation systems related to the thermal transmittance, disregarding the role of the mass, refer to calculation methods regarding theoretical hypothesis of stationary heat transfer system allowing more simplified operation. On the contrary, to evaluate the role of thermal inertia, and then analyse the performance of building even in summer, you must refer to the dynamic state analysis that require more complex calculation methods, which presuppose high abilities.

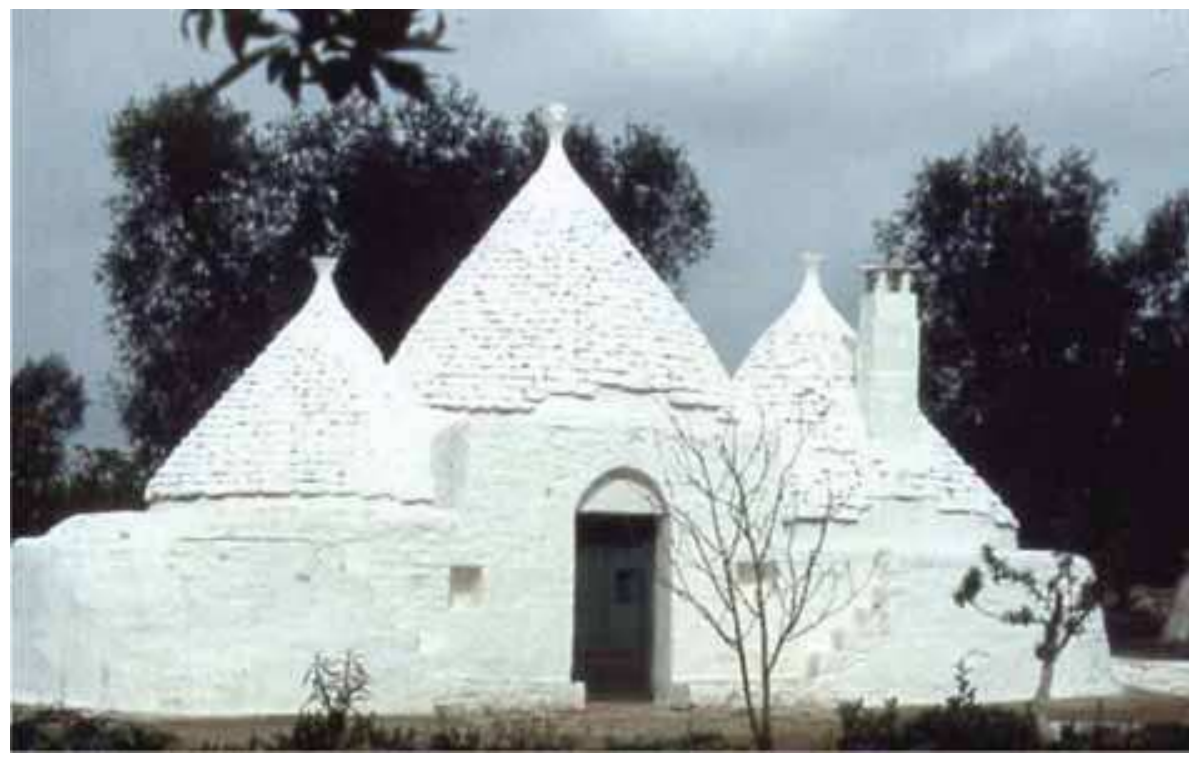




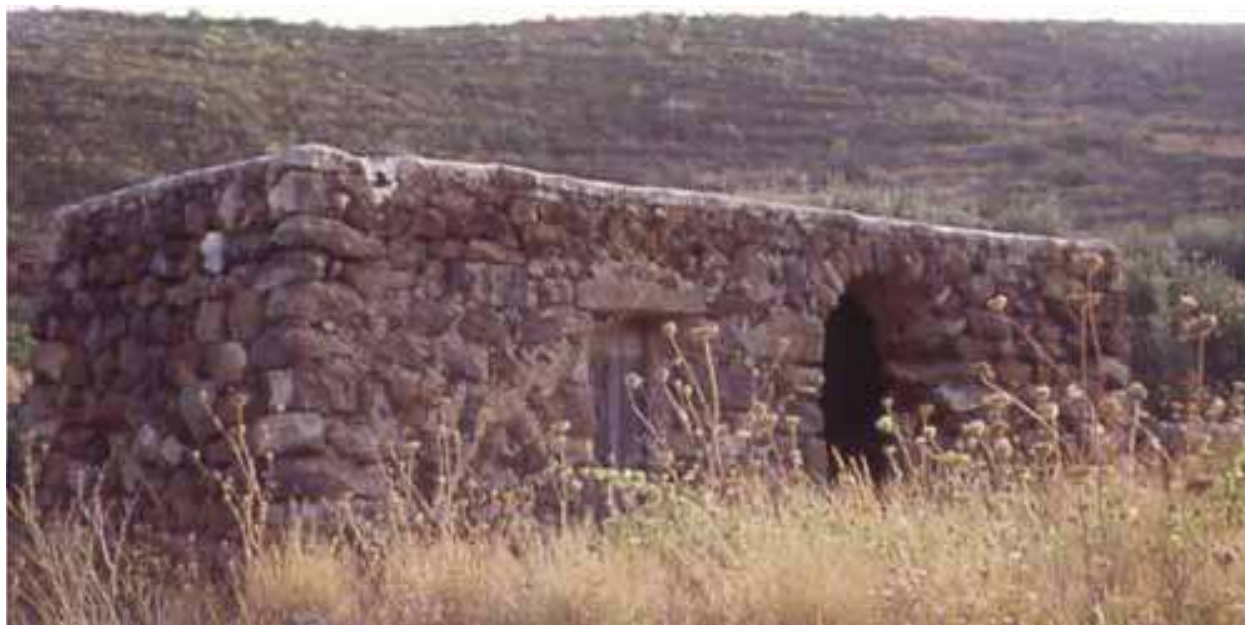

Figs. 13 - 14. Traditional building typologies. The use of appropriate materials, the bioclimatic relationship with the context contribute to maintain a constant internal microclimate without integration systems. "Dammusi" of Pantelleria and Apulian "trulli" are known as references in hot climates: the light painting favours the reflection of solar incident radiation.

\section{Normative guidelines}

As references, we examine the normative guidelines given by three major types of national regulations.

The factor of mass generally is not considered in the regulatory in cold climate areas.

As an example we can consider the CasaClima regulation of the Autonomous Province of Bolzano, which considers the issue identifying three types of structures depending on the weight of the principal components corresponding to reference categories and the choice should be included in calculation system.

The evaluation concerns only the heating energy demand and the choice of different systems is carried out in order to take into account the capacity of energy accumulation of the building in accordance with the use of passive heat energy.

For the calculation it is important to consider different types of construction: i.e. wooden buildings without massive components inside or buildings with application of massive components, as old buildings thick-walled of stone.

For the evaluation of thermal inertia, protocol ITACA, Italian national reworking based on Green Building Challenge rating system, provides following directions: the calculation of the coefficient of thermal lag of each opaque facades according to UNI 10375, and the determination of the coefficient of average lag, weighing coefficients of the surfaces on the basis of their areas. Then this protocol assigns a score ranging from -1 to +5 to this coefficient. 


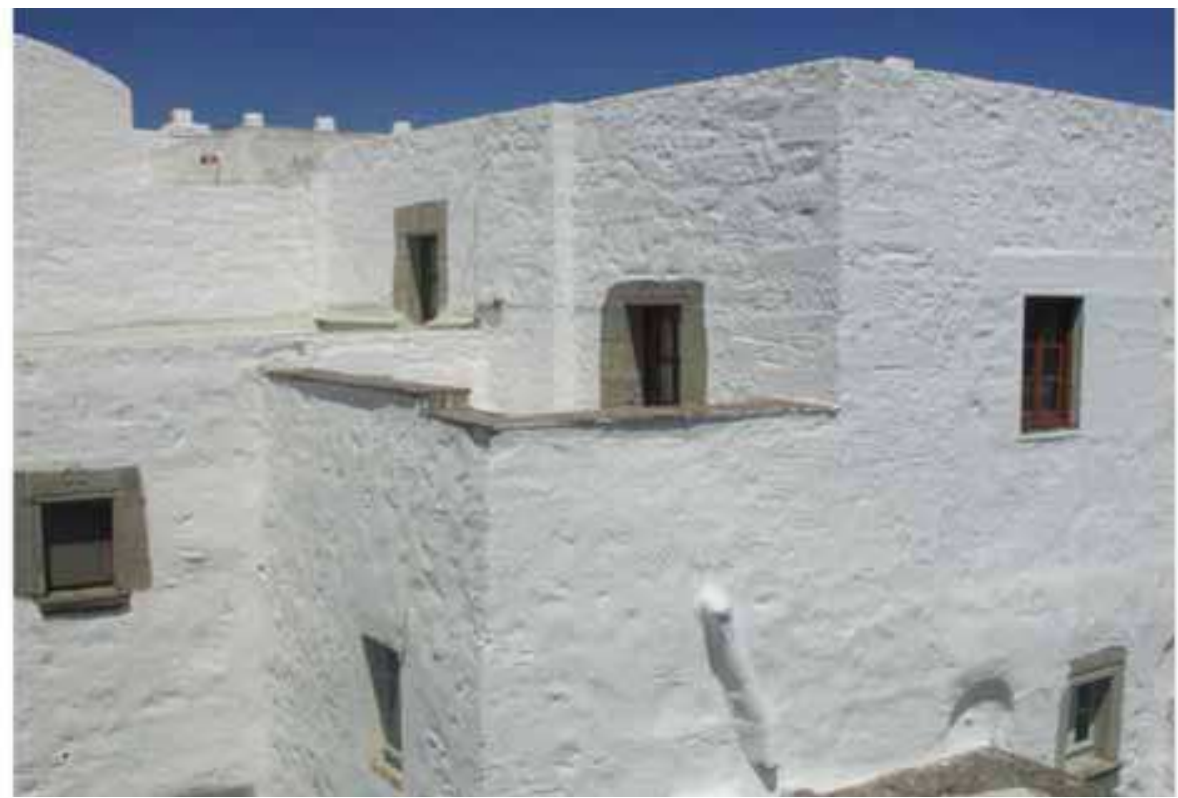

Fig. 15. Architecture and climate. The relationship with the climate and building traditions, often linked to local material availability, connotes typical construction

It makes equal to the value 0 , corresponding to the minimum acceptable performance, the time lag of 8 hours; the value 3 , corresponding to a significant improvement of the common mainstream practice, the time lag of 11 hours. Beyond 12 hours it will be assigned 5 points, equivalent to considerably advanced performances compared to best practice in use. The strategies tend to the use of heavy masonry shell, characterized by high thermal capacity and low conductivity. So, the combined action of thermal insulation and capacity of the system contributes to mitigate the indoor effects of external thermal variation. The D.L. 311/06, in force in Italy since February 2007, while focusing attention on the thermal transmittance of the envelope and on the winter heating of the building, establishes some requirements referring to the role of the mass related to the energy efficiency of buildings in summer.

In particular, Annex I, calls the designer to pay attention in order to limit the energy requirements for air conditioning in summer and to keep down the temperature onside. It is important to evaluate the performances of shields applied on glazed facades to reduce the contribution of solar heat due to radiation and to encourage the natural ventilation of the building, integrating it with mechanized systems, taking advantage from the distribution of locals.

With regard to the mass the D.L. 311/06 requires minimum values for the main building components. Excluding climatic zone F, for all locations characterized by an average monthly value of radiance on the horizontal plane during the month of maximum summer insulation greater than or equal to $290 \mathrm{~W} / \mathrm{m}^{2}$, the value of the mass of the shell should be greater than $230 \mathrm{~kg} / \mathrm{m}^{2}$. 
The purpose is to contain the oscillations of the temperature indoor in relation to the solar radiation.

\section{Conclusion}

The role of heat inertia, although extremely important in the characterization of energy efficiency of buildings in summer, cannot leave aside a more general design strategy aimed to a correct relationship with the environment. Among the main parameters the most important are the location, the shape and orientation of the building: southern orientation and shade considerations are some of the basic features that distinguish passive house construction.

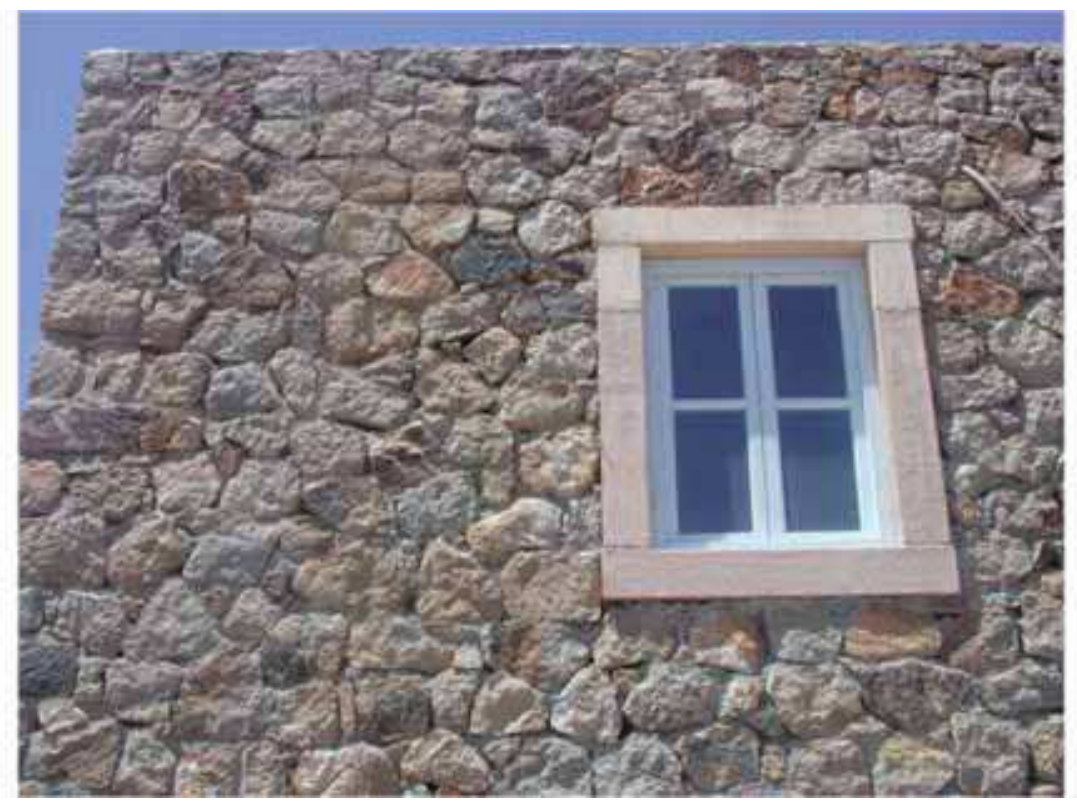

Fig. 16. In hot weather the problems related to overheating in summer exceed those for winter heating. Cooling systems increase consumption and tends to cause critical energy peak.

The ratio of dispersing surfaces and volume is an index of energy efficiency and it is considered a reference for regulations.

Other features of a passive house consist of an opportune distribution of rooms and functions, construction typology, use of energy-efficient window glazing and frames (windows - glazing and frames, combined - should have U-factors not exceeding 0.80 $\mathrm{W} / \mathrm{m}^{2} \mathrm{~K}$ with solar heat-gain coefficients around $50 \%$ ), application of solar shields. Particular important is natural or mechanical ventilation system - which may play an important role in summer cooling, encouraging the air change in the night (most of the perceptible heat in the exhaust air is transferred to the incoming fresh air) - and passive 
preheating of fresh air which may be brought into the house through underground ducts that exchange heat with the soil.

It is fundamental to integrate consciously energy-saving factors to realize buildings characterized by conditions of natural hydrothermal comfort with minimal energy use.

\section{References}

AA.VV. (2001), Costruire sostenibile: il Mediterraneo (Cuore Mostra SAIE), Alinea, ISBN 888125176-0, Firenze

AA.VV. (2005), Abitare in futuro - Città, quartieri, case, Be-ma, ISBN 88.7143.262.2, Milano

AA.VV. (2006), L'Italia si trasforma. Città in competizione, Be-ma, ISBN 10:88.7143.271.7, Milano

AA.VV. (2008), +Qualità-Energia. Per costruire sostenibile, Be-ma, ISBN 978-88-7143-291-5, Milano

Barucco, M.A., Trabucco, D. (2007), Architettura_Energia, Edicom, ISBN 978-88-86729-72-7, Montefalcone (Gorizia)

Boeri, A. (2007), Criteri di progettazione ambientale, Delfino, ISBN 978-88-89518-35-9, Milano

Boeri, A. (2006), Criteri di efficienza energetica per gli involucri degli edifici, in L'Ufficio Tecnico n³/06, Maggioli, Rimini, pp. 32-39, ISSN 0394-8293

Boeri, A. (2007), Efficienza energetica estiva degli edifici: il ruolo dell'inerzia termica, in L'Ufficio Tecnico n5/07, Maggioli, Rimini, pp. 24-30, ISSN 0394-8293

Hendriks, Ch. F. (2001), Sustainable construction, Aeneas technical publishers, The Netherlands Longo, D. (2007), Decostruzione e riuso, Alinea, ISBN 978-88-6055-122-1, Firenze

Novi, F. (1999), La riqualificazione sostenibile, Alinea, Firenze

Smith, P. (2004), Eco-Refurbishment, Architectural Press, Oxford 


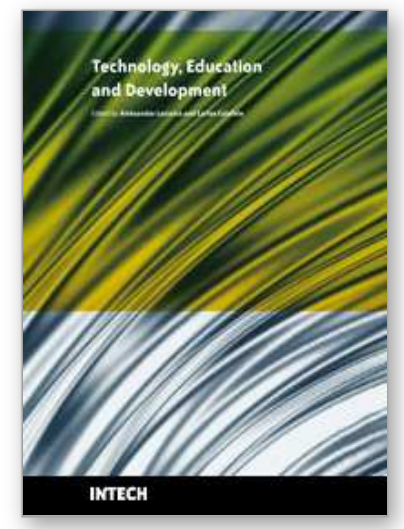

\author{
Technology Education and Development \\ Edited by Aleksandar Lazinica and Carlos Calafate
}

ISBN 978-953-307-007-0

Hard cover, 528 pages

Publisher InTech

Published online 01, October, 2009

Published in print edition October, 2009

The widespread deployment and use of Information Technologies (IT) has paved the way for change in many fields of our societies. The Internet, mobile computing, social networks and many other advances in human communications have become essential to promote and boost education, technology and industry. On the education side, the new challenges related with the integration of IT technologies into all aspects of learning require revising the traditional educational paradigms that have prevailed for the last centuries. Additionally, the globalization of education and student mobility requirements are favoring a fluid interchange of tools, methodologies and evaluation strategies, which promote innovation at an accelerated pace. Curricular revisions are also taking place to achieved a more specialized education that is able to responds to the society's requirements in terms of professional training. In this process, guaranteeing quality has also become a critical issue. On the industrial and technological side, the focus on ecological developments is essential to achieve a sustainable degree of prosperity, and all efforts to promote greener societies are welcome. In this book we gather knowledge and experiences of different authors on all these topics, hoping to offer the reader a wider view of the revolution taking place within and without our educational centers. In summary, we believe that this book makes an important contribution to the fields of education and technology in these times of great change, offering a mean for experts in the different areas to share valuable experiences and points of view that we hope are enriching to the reader. Enjoy the book!

\title{
How to reference
}

In order to correctly reference this scholarly work, feel free to copy and paste the following:

Andrea Boeri and Danila Longo (2009). Criteria for Promotion of Low Energy Buildings in Europe. The Italian Case, Technology Education and Development, Aleksandar Lazinica and Carlos Calafate (Ed.), ISBN: 978953-307-007-0, InTech, Available from: http://www.intechopen.com/books/technology-education-anddevelopment/criteria-for-promotion-of-low-energy-buildings-in-europe-the-italian-case

\section{INTECH}

open science | open minds

\section{InTech Europe}

University Campus STeP Ri

Slavka Krautzeka 83/A

51000 Rijeka, Croatia

Phone: +385 (51) 770447

Fax: +385 (51) 686166

\section{InTech China}

Unit 405, Office Block, Hotel Equatorial Shanghai

No.65, Yan An Road (West), Shanghai, 200040, China

中国上海市延安西路65号上海国际贵都大饭店办公楼 405 单元

Phone: +86-21-62489820

Fax: +86-21-62489821 
www.intechopen.com 
(C) 2009 The Author(s). Licensee IntechOpen. This chapter is distributed under the terms of the Creative Commons Attribution-NonCommercial-ShareAlike-3.0 License, which permits use, distribution and reproduction for non-commercial purposes, provided the original is properly cited and derivative works building on this content are distributed under the same license. 